\title{
Opinions on Innovation of Tourism Planning System in Era of Creative Tourism
}

\author{
Ying Dai \\ Changjiang Polytechnic, Wuhan, Hubei, 430074, China
}

Keywords: Creative tourism, Tourism planning system, Innovative significance, Innovative content.

\begin{abstract}
With the continuous improvement of people's living standards, their requirements for the tourism are becoming higher and higher, and the traditional tourism modes relying on the nature haven't been able to meet people's needs for sightseeing. The people in the new era pay more attention to the spiritual connotation and cultural content of tourism, and pursue more original, creative and imaginative tourism modes. Under this background, the creative tourism was born at the right moment. Many western countries have pioneered the creative tourism to lead to a new reform wave in the tourism industry. The concept of creative tourism also has been integrated into China's tourism industry gradually to start the reform of tourism industry in upgrading and transformation. In this paper, the author's opinions on the innovation of China's tourism planning system in the era of creative tourism are elucidated.
\end{abstract}

\section{Introduction}

People have gradually entered a new era of the Experience Economy, and the tourists are no longer satisfied with the simple visiting but pay more attention to the individualization of tourism, including the tourism modes, tourism content, service quality, etc. Tourists hope that the tourism can meet their needs in all aspects more and they can design and produce the tourism in a way. Meanwhile, people prefer to experience the leisure and entertainment on their trips. This demand is growing, so more developers and tourism enterprises create some theme tourism in the traditional landscapes, such as the rural experience tourism and theme parks, which are more entertaining and creative, and become more and more popular with the tourists and praised by them highly. China's tourism industry is also seeking the innovation and changing gradually for the demand of the home consumers. The promulgation of the Tourism Law and the state's all supportive polices for the tourism industry provide a foundation for the transformation of China's tourism industry. In addition, China has established the strategy for changing the tourism industry from the extensive form to the intensive form. Under these premises, creative tourism is an inevitable way for the reform of China's tourism industry.

\section{Brief introduction of concept of creative tourism}

Two scholars from New Zealand put forward the concept of creative tourism for the first time in 2000, who defined the creative tourism as the creative tourism products based on the active participation in the tourism process and the experience learned from the holiday destinations with the help of some culture or skill of the country or community, in order to provide the tourists with the creative potential for development. A Chinese tourism scholar, Li Wuwei, believes that the creative tourism is a development model, which integrates the thinking mode and model of the creative industry into the tourism industry, including the innovation of the tourism resources, products, services and so on. When people have more and more spiritual needs, in order to meet their higher needs, the market will constantly innovate and create new industries based on the original industrial models, which is the source of the creative industries and is highly raised for individual creative industries. The practice has proved that the creative industries have a strong influence and penetration in all industries, and have strong interaction with other industries, so the implementation of creative 
tourism has a very reliable basis. The key point of the creative tourism is the excavation of the spiritual level. Its main content is to re-integrate and utilize the resources of tourism and creative industries on the basis of culture after creative and technical processing. This tourism mode is very different from the previous diversified and high-quality modes, which can improve the attraction of the tourism areas greatly, promote the development of the tourism industry, and is conducive to the inheritance and promotion of culture.

\section{Significance of innovation in tourism planning system under development trend of creative tourism}

"The planning shall be ahead of the tourism development", which reflects that the tourism planning is the basis for the development and innovation of the tourism industry. Essentially, the tourism planning is the plan and deployment of the overall development goals and modes of the tourism industry in the mainland of China, which is the overall planning based on the relevant elements for the development of the tourism areas and the guidance for the tourism industry in the regions. The tourism industry in China rose late, but still has developed for 30 years. In the past 30 years, the tourism industry has gradually changed from the most basic stage of tourism planning to the market-oriented stage, and then developed to the integrated tourism planning stage of destinations. After the summary of tourism development in the past 30 years, it is obvious that the concept of tourism planning is changing and perfecting with the development of social form and market. Resources, market, products and marketing are the main contents of the transformation of the planning system. The innovation of the tourism planning system reflects the dynamic characteristics of the tourism industry, such as the mass tourism and leisure tourism at the beginning of the rise of the industry, the innovative health tourism to meet people's needs, and the creative tourism that is more popular with the consumers today. In order to meet the consumers' needs better and promote the development of the tourism industry, we must follow the social trend, update the planning of the tourism system according to the market needs, and lead the tourism industry to develop towards the creative tourism. Meanwhile, this is also an important foundation for the regional tourism industry to occupy a place in the fierce market competition. Usually, the contents of the past tourism planning systems were the requirements in some international standards, which couldn't adapt to the current era of Experience Economy and creative tourism obviously, so it is urgent to innovate and adjust the current planning system.

\section{Innovative content of tourism planning system}

\subsection{Experience tourist projects}

Tourism projects are the embodiment of the development of tourism resources. In the current tourism planning, tourists' most important experience is realized through the tourism projects. In the face of higher and higher demands of the tourists for the tourism experience, various tourism development enterprises have regarded the tourism projects as the key content for the development of the tourism industry. Creativity is difficult in all industries, especially in the tourism industry, which has been the focus and difficulty of the tourism industry since the rise of the tourism industry, especially in the tourism projects on better tourism experience for tourists. Many tourism scholars are keen on researching the creativity of the tourism projects, and have got some innovative methods and principles for the tourism projects in practice, which provide some guiding significance for the creativity of the tourism projects in the era of creative tourism. Under the background of creative tourism, in order to improve the tourists' experience effect better, the tourism projects need to combine the original innovative methods and principles to highlight the characteristics of tourism areas, and then add the era elements based on them. The traditional project design methods have always been built by stacking the projects without the consideration of the internal relations among the projects, so the project design lacks the integrity. Summarize all scholars' innovative principles 
for the projects: first of all, implement the construction of leisure and entertainment projects to increase the experience atmosphere for the tourists. In the era of Experience Economy, people pay more attention to their own experience. For the creative tourism, it is requested to strengthen the tourists' participation and experience.

In the design of creative tourism projects, first of all, enhance the interactivity between the projects and the tourists, increase the interestingness and experience of the entertainment projects, and transfer the tourists' passive visiting into active experience through these tourism projects. Secondly, increase the use of scientific technological elements in the design of tourism projects. Creative industries are the emerging industries in the era of modern information technology, which contain many high-tech technical elements. The application of these high-tech elements to the construction of tourism projects is of great value to the innovation of tourism projects and the enhancement of tourists' experience. In addition, the ecology, culture, science and technology and others can be combined to improve the effect of the culture, ecology and other soft elements on the innovation of tourism projects to meet the tourists' tourism experience. The most successful tourism project with the creative technical elements in the world is the famous Disneyland Park. Finally, the most important in the creativity of tourism projects is how to attract the tourists, provide the tourists with a variety of sensory stimulation, and enhance the tourists' experience. The demands of current tourists are more individual and flexible than those of the traditional tourists, so the project design shall focus on the needs of the tourists, take the humanization as the purpose, and improve the quality of the projects. However, people's experience and feelings are usually obtained through all sensory organs, so the project design shall also focus on the mobilization of all sensory organs to stimulate the creative potentials of the tourists, thus meeting their tourism needs.

\subsection{Diversification of tourism resource}

China's tourism planning has always followed the national standards, and most of the tourist attractions are the natural landscapes and cultural relics. Although the development time of the tourism industry in China is relatively short, many cultural relics and natural landscapes have been overdeveloped without the innovative elements, which have been unable to meet the increasingly changing needs of the tourists and have lost the attraction to the consumers. Therefore, the content innovation is the foundation for the thorough innovation of tourism industry.

Firstly, expand the scope of the tourism resources and enrich the resources to change the phenomenon that the current tourism resources are limited to the natural landscapes and cultural relics, avoid the overdevelopment of the cultural relics, and protect the cultural relics to a certain extent. In virtue of the creativity and flexibility of creative industries, we can change the limitations of the tourism resources, and absolutely can add the interesting, technological and fashionable elements into some resources that are not originally qualified for the tourism to develop some resources that are not easy to develop and social elements into the tourism resources. There are many resources with the qualification for development, such as the modern museums, animation parks, historical and cultural blocks, all of which can become the creative tourism resources. There have been some successful typical examples, such as the National Opera of Lyon, and Tianzifang in Shanghai, China.

Secondly, the tourism resources in the era of creative tourism pay more attention to stimulating the tourists' creative experience and satisfying their participation and experience, and ultimately satisfying their novelty-seeking psychology. Because only by meeting the psychological needs of tourists can the tourism industry develop permanently. Therefore, under such a premise, for the creative tourism, the evaluation of tourism resources shall be based on the experience and meet the current market demands and the consumers' psychological needs. Finally, the era of creative tourism provides new paths for the integration and transformation of the tourism resources. The creative work for the development of the creative tourism resources is a growing process out of nothing, and also a process turning the thought and inspiration into the materials. Some scholars have proposed to show the cultural resources to the tourists by telling stories. The process of transforming the cultural capital into the sensibility is a process of developing the creative tourism resources. 


\subsection{Creativity of tourism products}

The tourism product system is the community of a batch of products formed by integrating the tourism resources, market, social economy, infrastructure and other elements in a region ${ }^{[2]}$. There are many kinds and forms of tourism products at present. The main differences among them are caused by the actual situations in different areas. The common forms are sightseeing, vacation, business, ecology, health sports, self-driving tour and scientific exploration. Under the background of the creative tourism, the tourism resources are expanding constantly, so there will be more and more creative tourism products with more innovation and interactivity. These can let the tourists feel their differences and can meet their participation and needs better. According to its purpose, the construction to be embodied is complex, but the operation can be started from two aspects. One is to add the creative ideas to the existing tourism products, and the other is to develop new products by combining the creative industries with the tourism industry. Firstly, excavate the tourism value of the traditional culture deeply, transform and dress up the existing tourism products properly with the current thinking modes and technologies, and enhance their vitality by adding the modern elements and scientific and technological elements. Secondly, the products themselves with the combination of the both are novel, and these fresh elements have some attraction to the tourists, such as to add the design, visual arts and craft in the new era into the tourism products, and the integration of these elements has been proven their effect in practice, such as the distinctive theaters, science and technology museums and museums. The typical representatives are the Broadway Theater Park in New York and the SOHO in London, which were designed creatively with the epochal and technological elements, such as the digital media and interactive game software. On the basis of current theory and practice, the theme parks, creative experience museums and characteristic leisure blocks can become a part of the creative tourism product system.

\subsection{Diversification of tourism marketing}

After the creative development of the tourism resources, projects and products, the most important thing is to sell the products, namely, to attract the tourists by some ways. This is also called marketing, which is the most important part in the tourism planning, and the core part of marketing is creativity. Especially in the era of creative tourism, the creativity for marketing is more important. According to the research and practice of many scholars, the creativity for the marketing can be carried out in two aspects mainly. The first is to create the brand of tourism creativity, which shall be based on the understanding of consumers' psychology. After the understanding of the consumers, create the brand to meet the psychological needs of consumers, and especially focus on the consumers' participation and experience to create a tourism brand with distinctive personality and prominent characteristics. The second is to develop a variety of marketing channels for the products, and enhance the propaganda and popularization of the tourism products. The main marketing modes of traditional tourism products are the trade fairs, news and travel agencies, which have not been able to keep pace with the times. However, for the creative tourism, the ways such as the network medium, film and television marketing and festival marketing can be added in virtue of the advanced information technology on the basis of the traditional modes.

\section{Summary}

The creative tourism has become a fashion trend for the current tourism industry, which is an inevitable product of the social and economic development, and the innovative creative tourism planning system is conducive to promoting the development of the tourism industry and social economy.

\section{References}

[1] Shi Weiwei, Research on the Innovative Construction of Tourism Resources Evaluation System Based on the New Trend of Tourism Development,Beijing Jiaotong University, 2016 
[2] Wang Degen, Qian Jia, Opinions on Innovation of Tourism Planning System in Era of Creative Tourism. Tourism Tribune, 2014, 29 (05): 13-15.

[3] Zhang Yurong, Zhang Yuling, Research on Development Path of Cultural and Creative Tourism Complex under Background of Creative Economy -- Taking Chongqing as an Example. Inquiry into Economic Issues, 2012 (09): 85 - $88+190$. 